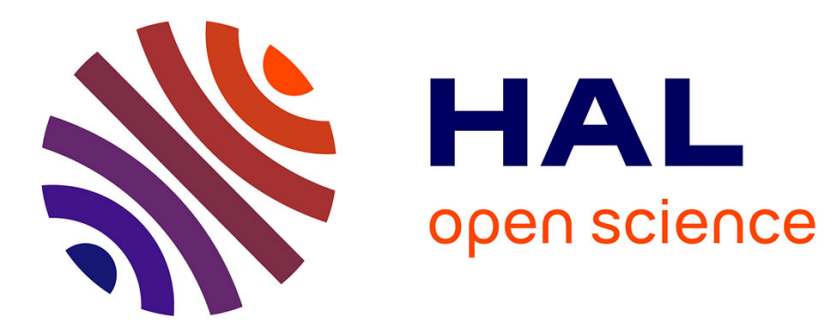

\title{
For Whom is the Problem of the Essential Indexical a Problem?
}

Isidora Stojanovic

\section{To cite this version:}

Isidora Stojanovic. For Whom is the Problem of the Essential Indexical a Problem?. Varol Akman, Paolo Bouquet, Richmond H. Thomason, Roger A. Young. Modeling and Using Context Lecture Notes in Artificial Intelligence 2116, Springer Verlag, pp.304-315, 2001. ijn_00460896

\section{HAL Id: ijn_00460896 \\ https://hal.science/ijn_00460896}

Submitted on 2 Mar 2010

HAL is a multi-disciplinary open access archive for the deposit and dissemination of scientific research documents, whether they are published or not. The documents may come from teaching and research institutions in France or abroad, or from public or private research centers.
L'archive ouverte pluridisciplinaire HAL, est destinée au dépôt et à la diffusion de documents scientifiques de niveau recherche, publiés ou non, émanant des établissements d'enseignement et de recherche français ou étrangers, des laboratoires publics ou privés. 


\title{
For Whom Is the Problem of the Essential Indexical a Problem?
}

\author{
Isidora Stojanovic \\ Institut Jean Nicod, 1bis avenue Lowendal, F-75007 Paris, France, and \\ Stanford University, Dept. of Philosophy, Stanford, CA 94305-2155, USA
}

\begin{abstract}
Philosophers used to model belief as a relation between agents and propositions, which bear truth values depending on, and only on, the way the world is, until John Perry and David Lewis came up with cases of essentially indexical belief; that is, belief whose expression involves some indexical word, whose reference varies with the context. I shall argue that the problem of the essential indexical at best shows that belief should be tied somehow to what is subsequently acted upon, and must make room for other relations than those properly predicated. But it does not show that belief cannot be modeled as a binary relation between an agent and some suitable object (pace Perry), nor that this object cannot be a proposition (pace Lewis).
\end{abstract}

\section{The Problem}

It is prima facie plausible to have the account of the notion of belief rely on these assumptions: $\mathrm{A}_{1}$ Belief corresponds to a relation between an agent and an abstract object, called a proposition; $\mathrm{A}_{2}$ Propositions are true or false depending on, and only on, the way the actual world is. However, it has been argued, most persuasively by John Perry and David Lewis, that such an account could not accommodate beliefs that are essentially indexical; that is, beliefs that one naturally expresses with the help of indexical expressions, such as "this", "today" or "I", which are known for being able to stand for different things in different contexts, without turning ambiguous thereby.

Perry and Lewis did not merely argue that some beliefs could not be expressed without indexicals. Rather, they were convinced that propositions could not provide an apparatus powerful enough to model belief, granted that belief helps in accounting for behavior. Here is a situation, borrowed from Perry [2], which illustrates the problem. Suppose that I went hiking, and had previously gathered from guides and other sources all possible information on the area where I went hiking. But I got lost. I know that to leave the wilderness I should take the Mt. Tallac trail, but I do not know whether it is the trail right in front of me, or some other one. Suddenly, I realize: "This is the Mt. Tallac trail! This is the trail I should take!" And so I move onto the trail. Now, it seems that I have gotten here a new piece of information, but of what sort can that information be? What distinguishes my beliefs before I figured out which trail I was looking at, from my beliefs afterwards? 
If one could show that there can be no proposition that I only came to believe when I figured out which trail I should take, and none that I ceased to believe either, one would be right to reject $\mathrm{A}_{1}$ or $\mathrm{A}_{2}$ - assumptions that I shall call the naive doctrine about belief. The bet of the naive doctrine is that whenever the same agent under the same circumstances assumes different behaviors, it is possible to come up with a proposition that will distinguish between the agent's beliefs. So, to refute the naive doctrine, one must be able to dismiss every proposition came up with as inadequate. What I shall do, then, is try to reach a proposition against which there will be neither theoretical nor empirical evidence.

The aim of the present paper is to show that propositions are tools good enough to classify beliefs, whether or not their expression involves indexicals. I shall not suggest that these should be the only available tools, or even the best ones - all I wish is to argue that the naive doctrine stands the challenge that has been taken to undermine it. My argument will not hinge upon the question of how propositions happen to be conceived. Whatever bears a truth value relative to, and only to, the way the world is, ought to be able to count as a proposition. Still, let me look at two conceptions of propositions, on both of which I shall draw a distinction between singular and general propositions, for the sake of convenience only.

\subsection{Two Conceptions of Propositions}

On their standard conception, propositions are identified with truth conditions. Truth conditions, in turn, are thought of as involving individuals, relations, or higher order relations that hold among lower order relations. (Properties are seen as unary relations.) As propositions bear their truth values relative to the way the world, $\mathrm{w}_{@}$, is, the truth schema for a proposition $p$ will look rather trivial:

$$
p \text { is true iff in } \mathrm{w}_{@}, p
$$

A proposition will be singular if it involves some individual, general if it involves none. Using the framework of predicate logic, we may represent singular propositions by open sentences accompanied with an assignment of values to the variables, and general propositions by closed sentences.

By way of illustration, consider an utterance of "Brian is smart" and another one of "He is smart" made in reference to Brian. Let $p_{1}$ be the proposition assigned to the first utterance and $p_{2}$ to the second. Then both $p_{1}$ and $p_{2}$ may be represented by the same open sentence with an assignment, $S x[$ Brian $\rightarrow x] .{ }^{1}$ Their truth schema will be:

\footnotetext{
${ }^{1}$ Since $p_{1}$ and $p_{2}$ turn out to be one and the same proposition, this conception of propositions ought to be considered as "coarse-grained". Some could think that as soon as propositions are thought of as involving individuals, relations, etc., they will be structured and therefore finegrained. To see that they need not be structured, instead of representing propositions by sentences, represent them by classes of logically equivalent sentences. E.g. for $p_{l}$, or equivalently $p_{2}$, take the class of sentences logically equivalent to $S x$, accompanied with the assignment of Brian to the variable $x$. And if there should remain a difference in grain between the two conceptions, it will be irrelevant to the discussion of the essential indexical.
} 
On an alternative conception, propositions are identified with sets of possible worlds. This will be their truth schema then:

$$
p \text { is true iff } \mathrm{w}_{@} \in \mathrm{p}
$$

The distinction between singular and general propositions can be easily drawn on the possible world conception as well. Assume that possible worlds differ from one another depending on which individuals get into which relations. Some worlds will be isomorphic. Two worlds are isomorphic iff the individuals of one world, $\mathrm{w}_{1}$, may be mapped onto the individuals of the other world, $\mathrm{w}_{2}$, by some one-one function $f$ such that if in $\mathrm{w}_{1}, \mathrm{Ra}_{0} \ldots \mathrm{a}_{\mathrm{n}}$, then in $\mathrm{w}_{2}, \mathrm{R} f\left(\mathrm{a}_{0}\right) \ldots f\left(\mathrm{a}_{\mathrm{n}}\right)$, and if in $\mathrm{w}_{2}, \mathrm{Ra}_{0} \ldots f \mathrm{a}_{\mathrm{n}}$, then in $\mathrm{w}_{1}, \mathrm{R} f^{-}\left(\mathrm{a}_{0}\right) \ldots f^{-}\left(\mathrm{a}_{\mathrm{n}}\right)$, for every $\mathrm{n}$, every $\mathrm{n}$-ary relation $\mathrm{R}$, and every individual $\mathrm{a}_{\mathrm{i}}$. (Reminder: $f^{-}\left(\mathrm{a}_{\mathrm{j}}\right)=\mathrm{a}_{\mathrm{k}}$ iff def $f\left(\mathrm{a}_{\mathrm{k}}\right)=\mathrm{a}_{\mathrm{j}}$.)

General propositions can be defined then as sets closed under isomorphism. That is to say, if some world belongs to the set that stand for a general proposition, every other world isomorphic to it must also belong to the set. Singular propositions, on the other hand, will distinguish among isomorphic worlds. By way of illustration, consider three extremely simple worlds, with only two individuals, Brian and Bill, and no other relation than the unary one of being smart and the binary one of being taller than. In $w_{1}$, Brian alone is smart and is taller than Bill. In $w_{2}$, Bill alone is smart and is taller than Brian. In $w_{3}$, Brian alone is smart but Bill is taller than Brian. Consider now an utterance of "Brian is smart and is taller than Bill", and let $p$ stand for the proposition assigned to it. We would like to say that if $w_{1}$ were the actual world, $p$ would be true, but not if either $w_{2}$ or $w_{3}$ were the actual world. But saying that in the possible world jargon must presuppose singular propositions. For there is no general proposition that may distinguish between $w_{1}$ and $w_{2}$, given that they are isomorphic. (Just take $f$ to map Brian onto Bill and Bill onto Brian.) For comparison, note that there are general propositions to distinguish between $w_{1}$ and $w_{3}$, as well as between $w_{2}$ and $w_{3}$.

The relationship between the possible world conception and the standard one is straightforward. The proposition associated to an utterance of "Brian is smart", as well as to an utterance of "He is smart" made in reference to Brian, will be the set of worlds characterized in terms of Brian's smartness, namely:

$$
\{\mathrm{w} \mid \text { in } \mathrm{w}, \text { Brian } \in S\}
$$

Note that if it turned out that, for every individual, there were a class of properties that together hold of, and only of, that individual, the distinction between general and singular propositions would be vacuous, but harmless.

\subsection{Believing Singular Propositions}

The notion of singular proposition implies that it should be possible to refer to an individual directly, without having to individuate it as whatever uniquely falls under this-and-such description. It is an open issue what secures direct reference. One 
certainly ought to bear some non-trivial relation to the things that one is directly referring to. Russell used acquaintance to that effect: "I say that I am acquainted with an object when I have a direct cognitive relation to that object, that is when I am directly aware of the object itself." "What matters to the present discussion is that singular propositions belong among the tools available to the naive doctrine, and, more importantly, that the naive doctrine may avail itself of assumptions on the conditions under which singular propositions come to be believed, such as: $\mathrm{A}_{3}$ If $p$ is a singular proposition about $\varepsilon$, and if a is an agent, then a can believe p only if $\underline{a}$ is suitably related to $\varepsilon$. Now, it has been argued that essentially indexical belief cannot be accounted for in any propositional framework, be it provided or not with singular propositions or any other device of direct reference. ${ }^{3}$

Let me clarify what the issue is. Suppose that, under the same circumstances, one behaves differently only if one entertains different beliefs. Then how sophisticated a machinery do we need to articulate those differences in belief? There might be more differences than general propositions allow us to make. In the hiking situation e.g., my promptness to move onto a particular trail can hardly, if at all, be accounted for without an appeal to the trail itself. But are there more differences than singular propositions allow us to make? That is the question I shall focus on. So, the moment I could say "This is the trail I should take", did I not acquire a de re belief about the Mt. Tallac trail, to the effect that I should take $i t$ ? Well, philosophers seem to agree that I could have had that same belief all along, which leaves my change in behavior unexplained. Perry's solution to the problem of the essential indexical was that there need be no change in what I believe, that is, in the conditions under which my beliefs are true. Instead, the difference in behavior would stem from the way in which I believe whatever it is that I believe. Thus when I think of the Mt. Tallac trail as of "this trail", nothing changes within my beliefs, only do I come to entertain my de re belief about the Mt. Tallac trail, to the effect that I should take it, under a different guise, picturing the res that my belief is about as the trail that I am looking at.

The view just sketched sees the structure of belief as essentially bipartite: what is believed is not the only thing that matters; what also matters is how that is believed. In what follows, I shall argue that there are no compelling reasons to go bipartite. The strategy, in a nutshell, will be to incorporate everything imparted upon the guise under which I entertain some belief, into the belief itself. Then the problem of the essential indexical turns out not to be a problem for the naive doctrine, as long as it takes care of the fact that beliefs, in the sense of the conditions under which beliefs are true, had better be tied to the particulars acted upon as a result of those beliefs; and also, of the fact that some relations, like that of demonstrating or of looking at when perceptual demonstratives are used, are not limited to their heuristic role, but matter to what is believed as well.

\footnotetext{
${ }^{2}$ [5], p. 16. For Russell, acquaintance is a necessary condition on the grasp of all propositions: "Every proposition which we can understand must be composed wholly of constituents with which we are acquainted." ([5], p. 23.)

${ }^{3}$ Perry wrote indeed: "The problem is not solved merely by replacing or supplementing [the view that belief is a relation between subjects and propositions conceived as bearers of truth and falsity] with a notion of de re belief." ([2], p. 34.) For our purposes, it will be safe to identify belief de re with belief whose argument must be a singular proposition.
} 


\section{In Quest of the Best Analysis of "This"}

Once again, here is the situation. I know that, to leave the wilderness, I should take the Mt. Tallac trail, but am unsure as to which trail it is. Then, say at 6 p.m. sharp, I am ready to say: "This is the Mt. Tallac trail! This is the trail I should take!" Now, what is the belief that I come to express? It had better be a belief I must have lacked, if my action of moving onto the trail is to be explained by a change in beliefs. Perhaps what I got out of the hiking guides were not de re beliefs about the Mt. Tallac trail, but merely general beliefs to the effect that there exists some trail, called Mt. Tallac, leading out of the wilderness. I would have had a belief we may gloss as:

$$
\exists x(\delta x \& y \text { should take } x) \text { [Isidora } \rightarrow y \text { ] }
$$

where $\delta$ stands for the relevant description. In contrast, identifying the Mt. Tallac trail deictically would earn me a de re belief to the effect that I should take $i t$ :

$$
y \text { should take } x \text { [the Mt. Tallac trail } \rightarrow x \text {, Isidora } \rightarrow y \text { ] }
$$

The worry with $\mathrm{p}_{1}$ is that I could have believed that proposition all along - or so it seems. For suppose that I had taken the Mt. Tallac trail on my way to the wilderness, and thousands of times before. The trail must have been familiar enough to me to have de re beliefs about it, in particular $\mathrm{p}_{1}$. But again, I could get lost, so $\mathrm{p}_{1}$ would not account for my moving onto the trail only once I could say "This is the trail I should take." 4

In hope of avoiding overstrong constraints on the cognitive relation borne to the constituents of the propositions believed, let us seek a better candidate than $\mathrm{p}_{1}$. It is crucial that my change in behavior occurred precisely at the moment at which I started looking at a certain trail as at the trail that I should take. So why not say that I simply came to have a de re belief about the Mt. Tallac trail, to the effect that it was not only the trail that I should take, but also the trail that I was looking at, glossed as:

I should take $x \& y$ looks at $x$ at $t$

$\mathrm{p}_{2}$

[the Mt. Tallac trail $\rightarrow x$, Isidora $\rightarrow y, 6$ p.m. $\rightarrow t$ ]

The worry, quite as before, is that it seems that I could have believed $\mathrm{p}_{2}$ all along. The case is somewhat harder than the previous one, for it is not clear what secures direct reference to some time, especially when the time referred to belongs to the future. But still, let us suppose that I had taken the Mt. Tallac trail on my way in, and that at some time earlier than 6 p.m., say at 5.57 p.m. sharp, I came to believe that I would be looking at the Mt. Tallac trail at 6 p.m., of which time I was directly aware somehow - e.g. I might have thought of it as of the time which was going to occur in exactly 3 minutes. But meanwhile, I have lost track of time, and have found myself

\footnotetext{
${ }^{4}$ One could still deny, however, that I continued to have de re beliefs about the Mt. Tallac trail, such as $\mathrm{p}_{1}$, after I got lost. One could thus hold that we must continuously bear a direct cognitive relation to every constituent of the singular propositions we believe. At some point, I would have ceased believing $\mathrm{p}_{1}$ to the detriment of a more general proposition, viz. that there existed some trail, named after Mt. Tallac, which I had taken on my way into the wilderness, and should take now to get out.
} 
in the same situation as before, knowing that I should take the Mt. Tallac trail, but not knowing which trail it was. Then $\mathrm{p}_{2}$, having already been among my beliefs, cannot account for my change in behavior. ${ }^{5}$

\section{A Tentative Solution, Worries and Replies}

With $\mathrm{p}_{2}$, the worry was that I could have believed that proposition before I decided to move onto the Mt. Tallac trail. So why not tie the proposition that I came to believe then not only to the moment at which I started looking at the Mt. Tallac trail as at the trail I should take, but also to my action of so looking at it? Events such as looking at something, reflecting on it, invoking it in memory, etc., may be plausibly considered as particulars also. Indeed, we refer to them, ascribe them properties, and relate them to other particulars. Given that events generate singular propositions just as other worldly things do, to explain my moving onto the trail, we simply need some suitable proposition among whose constituents is the event that corresponds to my looking at the Mt. Tallac trail, at 6 p.m., as at the trail I should take. Let $\varepsilon$ stand for that event. When I got ready to say "This is the trail I should take" and to move onto the trail, I came to have, inter alia, a de re belief about $\varepsilon$, to the effect that the Mt. Tallac trail was the object of $i t$. Then what I came to believe may be glossed as:

$y$ should take $x \& y$ undergoes $z$ at $t \& x$ is the object of $z$

$\mathrm{p}_{3}$

[Isidora $\rightarrow y$, the Mt. Tallac trail $\rightarrow x, 6$ p.m. $\rightarrow t, \varepsilon \rightarrow z$ ]

There are two worries with $\mathrm{p}_{3}$ worth addressing. One comes from our layman's intuitions on the matter, and holds that there is just no plausibility to the idea that if I say "This is the trail I should take", I should ever express a belief about any mental event, in particular the one that I am undergoing. The other worry comes from the feeling that particulars corresponding to our mental events should, in principle, be possible to apprehend under different guises. Chances are then that the same agent could be endowed with the same de re beliefs about the same mental event, while still assuming different attitudes to it, therefore behaving differently.

In order to dispel the first worry, let me appeal to the notion of an "unarticulated constituent", introduced by John Perry in [3]. Perry pointed out that the belief I would express by saying "It is raining" must include a particular place among its constituents, which place bears upon the truth of my belief; however, I do not need to have a representation of that place, nor do I need to conceptualize it. I do not need to be reflecting upon that place, or to be consciously attending to it. That place is then an unarticulated constituent of my belief. It is relevant to the truth of my belief, but pretty much irrelevant to the nature of my behavior. The same insight applies to time. And the same insight, it seems, applies to events in general. The naive doctrine cannot be accused, then, of letting action hinge upon the ability to conceptualize thoughts and other mental events, for it does not. The issue is whether propositions are good tools to account for different behaviors under the same circumstances.

\footnotetext{
${ }^{5}$ Again, one could suggest that when I lost track of time, I also lost my grip on the relevant time, 6 p.m., losing thereby all my de re beliefs about it.
} 
Propositions that have among constituents the mental event that an agent happens to undergo clearly do not commit to the idea that every action of ours should involve company of fully articulated thoughts about those thoughts themselves.

Now, does the second worry go through? Is it possible, for instance, to so modify the hiking situation as to let me have believed $p_{3}$ all along, even before I figured out, at 6 p.m., which the Mt. Tallac trail was, even before $\varepsilon$ came into existence? That seems hard. There is a more general question, though: is it possible to bear a direct cognitive relation to some mental event, of the sort required to have de re beliefs about it, without actually undergoing that mental event? In particular, can anyone else than the person undergoing $\varepsilon$ grasp propositions about $\varepsilon$, such as $\mathrm{p}_{3}$ ?

I shall not try to settle that question. What I shall do instead is argue that neither way will the naive doctrine come under threat. In other words, I shall argue to the conditional: even if it should turn out that one can directly refer to mental events that one does not undergo, there are ways for the naive doctrine to account for the change in behavior.

As with any conditional, let us suppose the antecedent, namely, that it is possible to refer to mental events directly, without undergoing them. To lend the idea a speck of plausibility, let us try to think of cases in which this sort of direct reference appears possible. Since it is dubious that in everyday life we come to be directly aware of mental events we do not undergo ourselves, it may be worthier to look at the case, say, of a neuroscientist who is working on mental processes. Suppose that a study is being carried out on several subjects, and that our neuroscientist is able to isolate particular mental events on the subjects' brain scans. Wouldn't he then be able to have de re beliefs about those mental events themselves? Whatever the answer to this question should be, let us assume, for the sake of the argument, that isolating a mental event on a brain scan secures direct reference to the event, and let us use this assumption to try to set out a pair of cases in which my beliefs would be exactly the same, yet I would behave differently.

Engaging in something of a science-fiction, suppose that, unbeknownst to me, I am constantly brain-scanned, as part of a study carried out on several subjects by a team of neuroscientists. As before, I decide to go hiking, and I get lost. At 6 p.m. sharp, as I stare at the Mt. Tallac trail, it dawns down on me that this is the trail that I should take, and so I move onto the trail. At the same time, $\varepsilon$ appears on my brain scan, so that everyone looking at my brain scan may now refer to $\varepsilon$ directly, and form de re beliefs about $\varepsilon$. In particular, let us assume that, knowing me wishful to leave the wilderness, all of our neuroscientists come to believe $p_{3}$ itself:

$$
\begin{aligned}
& y \text { should take } x \& y \text { undergoes } z \text { at } \& x \text { is the object of } z \\
& \text { [Isidora } \rightarrow y \text {, the Mt. Tallac trail } \rightarrow x, 6 \text { p.m. } \rightarrow t, \varepsilon \rightarrow z \text { ] }
\end{aligned}
$$

Now, add to the situation that I also happen to be part of the team, and have access to the brain scans of some of the subjects. So let us contrast two variants of this situation. On one variant, the subject whose brain scan I have access to is not myself, whereas on the other, it is myself - although, of course, I am ignorant of that. Suppose furthermore that I had been instructed, were I to isolate on the brain scan some mental event having the Mt. Tallac trail for object, I should remain still until further instruction. So here is what we get: I go hiking, get lost, but end up figuring 
out which trail I should take. Now, on one variant of the situations, as usual, I move onto the trail. But on the other, $\varepsilon$ appears on the brain scan, and no later than I have spotted it do I decide to remain still, as instructed.

Despite its highly fictional nature, the situation is challenging in that, if we give credit to the naive doctrine, it seems that we will end up endowing me with exactly the same beliefs. But in the case in which I happen to have access to my own brain scan, one may be inclined to say that I came to believe $\mathrm{p}_{3}$ "twice", under different guises: a reflexive guise vs. a deictic guise. There is an intuitive difference between those manners of coming to believe $\mathrm{p}_{3}$, which might explain the difference in my behavior. But how can the naive doctrine make use of that difference, if it is to be a difference in how I believe things, and not in what I believe? I contend that it can. In the case in which I do not move onto the trail, I do have an additional de re belief about $\varepsilon$, to the effect that it is the mental event that I have isolated on the brain scan. ${ }^{6}$

\subsection{What Perry Objected to the Naive Doctrine}

Perry's conviction that the notion of de re belief cannot handle the problem of the essential indexical is partly due to focusing on only one way of associating de re beliefs with the essentially indexical ones. An essentially indexical belief, recall, is a belief one naturally expresses with the help of indexicals. Thus, in the atomic case, let $\mathrm{P}$ be some predicate and $\mathrm{t}$ some indexical term. Perry seemed to think in [2] that the only singular proposition an utterance of "Pt" could be associated with was $\mathbf{P} x[\mathrm{~b} \rightarrow x]$, with $\mathbf{P}$ the property denoted by "P" (leaving tense aside, for the sake of simplicity), and $b$ the individual referred to with " $l$ " in the context of the utterance. For instance, if I say "This is an outward trail" in reference to the Mt. Tallac trail, the de re belief associated to my utterance would merely consist in the property of being an outward trail ascribed to the Mt. Tallac trail. It comes then as little surprise that such "atomic" de re beliefs are not powerful enough to account for behavior. As Stalnaker noted: "the lesson of the examples of essentially indexical belief - the examples that motivate Perry's account - is that indexicals are essential to the

\footnotetext{
${ }^{6}$ There are two more worries with the view that uses propositions such as $\mathrm{p}_{3}$. One, concerning infinite regress, rests on the assumption that every occurrence of "this" must be further analyzed in terms of the complex "this mental event". But one may reply that "this" allows for such semi-descriptive occurrences, analyzable further down, as well as for purely referential occurrences, any of which will stop the regress. I shall tackle a closely related question shortly.

The other worry, concerning circularity, rests on the assumption that it is possible to individuate beliefs by their contents; so, how could the content of some belief have the belief itself as a constituent, since one would then have to individuate the belief itself in order to individuate its content, yet this content is necessary to individuate the belief? Without rejecting the assumption, one may simply define contents of beliefs inductively. Let s stands for the belief that I would express by saying "This $\varphi s$ " in reference to some b. As any mental episode, $s$ extends through time, say from $t_{i}$ to $t_{j}$. Suppose that the interval $[i, j]$ is well-ordered by its linear order, and let the content of $s$ at $t_{i}$ be empty by definition, and for every $k$ : $i<k \leq j$, let the content of $s$ at $t_{k}$ consist of b's ping and of b's being the most salient thing relative to the belief individuated by the sum of the contents of $s$ at $t_{l}$, for every $1: i \leq 1<k$. In spite of sketchiness, this hint at a definition reveals that the worry should not be paid great attention.
} 
information itself and are not just part of the means used to represent it." ${ }^{, 7}$ A sentence built out of some predicate and the demonstrative "this" need not be limited to ascribing only the predicated property to what the demonstrative stands for. There is no reason it should not encompass the property of being currently looked at, e.g.

To sum up, Perry would have been right to say that the problem of the essential indexical is not solved merely by appealing to a certain fairly restricted class of de re beliefs. But this is clearly not to say that de re beliefs just cannot supply a solution to the problem. To be sure, the solution I have hinted at does not presuppose that for every action, there is exactly one belief entertained by the agent that explains it. Rather, all the beliefs the agent entertains are to be taken into account, the task of explaining action calling for a holistic approach. ${ }^{8}$

\section{Lewis' Challenge}

David Lewis gave birth to the thesis that "sometimes propositional objects won't do" as objects of beliefs. ${ }^{9}$ To get a grip on Lewis' argument, we should imagine two "omniscient" hikers wishful to leave the wilderness. One of the hikers is looking at the Mt. Tallac trail, while the other happens to be looking at some other trail that does not lead out of the wilderness. For every possible proposition, the hikers ex hypothesi know whether it is true or not. In terms of possible worlds, they know exactly which world is theirs. But neither knows, as Lewis would claim, whether he should move or not onto the trail, since neither knows which of the two hikers he is, nor which trail he is looking at.

I shall argue that propositions will do on both conceptions of propositions. Let the hiker looking at the outward trail be Brian, and let the other hiker be Bill. Then these belong among the propositions known by Brian and Bill:

$$
\begin{array}{cl}
y \text { should take the trail that } y \text { is looking at }\left(\text { at } \mathrm{t}_{0}\right)[\mathrm{Brian} \rightarrow y] & \mathrm{p}_{1} \\
y \text { should not take the trail that } y \text { is looking at }\left(\text { at } \mathrm{t}_{0}\right)[\mathrm{Bill} \rightarrow y] & \mathrm{p}_{2}
\end{array}
$$

Grasp of singular propositions like $\mathrm{p}_{1}$ presupposes some non-trivial relation to the individuals they involve. Brian can believe $\mathrm{p}_{1}$ only if he is acquainted with himself, but if he is unsure as to what to do, he should be acquainted with himself not only through the relation through which all of us are acquainted with ourselves, but through some other relation as well. There should be two relations relating Brian to himself and securing direct reference to himself, and he does not even have to realize that the individuals he is related to are one and the same (Brian himself, to wit.)

Russell, for instance, sought a relation of acquaintance that would always force you to realize that the things you are acquainted with are one and the same (provided, of course, that they are one and the same.) If, unlike Russell, one leaves room for the possibility of being doubly acquainted with something, will one have to acknowledge

\footnotetext{
${ }^{7}$ [7], p. 148 .

${ }^{8}$ From a technical point of view, though, there is little to worry about, since an agent's beliefs, finite in number, can be merged into a single belief using conjunction.

${ }^{9}$ See [1], p. 134.
} 
that "propositions won't do"? Suppose, for the sake of the argument, that Brian is doubly acquainted with himself. One of the two relations he bears to himself is the relation, call it self-acquaintance, we all bear to ourselves and only to ourselves. It is through this relation that we normally grasps singular propositions we are involved in. (I should emphasize that the mere possibility of being self-acquainted with oneself does not mean that one thereby has any non-propositional or de se beliefs about oneself.) So suppose that Brian's grasp of $\mathrm{p}_{1}$ does not rely on selfacquaintance. Now, $\mathrm{p}_{1}$ is not the only proposition we can appeal to. Let $\varepsilon_{1}$ stand for that mental event undergone by Brian at $\mathrm{t}_{0}$ while looking at the outward trail, and let $\varepsilon_{2}$ stand for the mental event undergone by Bill at $t_{0}$ while looking at the inward trail. Both Brian and Bill are deemed to know these two propositions as well:

the agent of $x$ should take the trail that he is looking at $\left[\varepsilon_{1} \rightarrow x\right] \quad p \varepsilon_{1}$ the agent of $x$ should not take the trail that he is looking at $\left[\varepsilon_{2} \rightarrow x\right] \quad \quad p \varepsilon_{2}$

Again, to grasp $p \varepsilon_{1}$, Brian must be acquainted with the things it involves, that is, with $\varepsilon_{1}$. Note that Brian is already acquainted with the mental event $\varepsilon_{1}$ through the relation of undergoing it. But if his knowledge of $p \varepsilon_{1}$ relied upon this straightforward relation to $\varepsilon_{1}$, Brian would not hesitate to move. Given that he hesitates, he must be doubly acquainted with $\varepsilon_{1}$ : through the relation of undergoing that mental event, and through another, no less direct relation. However, it is not even clear whether double acquaintance with mental events is possible. Perhaps the only mental events one can be acquainted with are those undergone by oneself. Then Brian could not grasp $p \varepsilon_{2}$, nor could Bill grasp $p \varepsilon_{1}$, if they were ordinary agents.

Whether or not it is possible to grasp propositions that involve other mental events than those undergone by oneself, I have argued that the naive doctrine stands the challenge. So suppose, for the sake of the argument, that Brian is doubly acquainted with $\varepsilon_{1}$, and that his grasp of $p \varepsilon_{1}$ does not rely upon the relation of undergoing that mental event. Let $\mathrm{R}$ be the relation that his grasp of $\mathrm{p} \varepsilon_{1}$ relies upon. Since $\mathrm{R}$ is a cognitive relation, we had better think of it as relating $\varepsilon_{1}$ to some other mental event of Brian's, $\eta_{1}$, rather than to Brian himself. Then our omniscient Brian must know this proposition:

$$
x \mathrm{R} y\left[\varepsilon_{1} \rightarrow x, \eta_{1} \rightarrow y\right] \quad \quad \mathrm{p} \eta_{1}
$$

Some may begin to fear here the threat of infinite regress. For in order to grasp $\mathrm{p} \eta_{1}$, Brian must be acquainted with $\eta_{1}$, yet he could grasp $\mathrm{p} \eta_{1}$ not through undergoing $\eta_{1}$, but through some other relation $\mathrm{R}_{1}$. Then there would be another mental event, say $\eta_{2}$, that $R_{1}$ relates $\eta_{1}$ to, and we would have another proposition, $\mathrm{p} \eta_{2}$, generated on the pattern of $\mathrm{p} \eta_{1}$. And so on, and so on. However, this "so on" does not automatically become a "so on ad infinitum". The naive doctrine is not threatened from infinite regress unless it has been presented with a case whose agent it would have to endow with an infinite number of propositions, all generated on the pattern of $\mathrm{p} \eta_{1}$ and $\mathrm{p} \eta_{2}$. But to present it with such a case would mean to postulate the existence of an agent who undergoes an infinite number of mental events. This strikes me as empirically impossible. 
Let me give you the general picture. The naive doctrine holds that whenever the same agent, under the same circumstances, behaves differently, a proposition can be found which he believes in one case only. Its opponents rest their challenge on a hypothetical case in which an agent believes the same propositions, but makes acquaintance of some individual involved in those propositions under two different guises. Certain acquaintance relations, such as self-acquaintance, or acquaintance with a mental event through undergoing it, do not leave room for any challenge whatsoever. But other manners of getting acquainted with something, which arguably leave room for the challenge, pull along the relation itself that the acquaintance relies on. The naive doctrine is then vindicated, because all it needs to do is generate a suitable proposition out of the relation thus supplied by its opponents. For the threat from infinite regress to arise, one would have to come up with a plausible case in which the agent is acquainted with his own mental events, but never through the relation of undergoing the event. But it appears that in any such case the agent would have to undergo an infinite number of mental events, which is not only implausible, but empirically impossible. At some point or another, one must stop and concede that the grasp of a proposition that involves some mental event relies on the relation of undergoing the event.

Lewis' challenge does not arise on the possible world conception either. Let $w$ be the actual world (that is, the world actual to Brian and Bill), and $v$ a possible world exactly like $w$, except that Brian and Bill had traded places, so to say. According to Lewis, Brian and Bill know exactly which world is theirs $-w$, to wit - , but are still unsure as to what to do. On this assumption, when Brian finally decides to move onto the trail, it cannot be in virtue of gaining any new propositional knowledge.

But there is a problem with this assumption itself. In one case, Brian does not know what to do, while in the other, he moves onto the trail, and the question is whether there is a proposition to distinguish between the two cases. The singleton $\{w\}$ distinguishes between them! In the case in which Brian wonders what to do, he knows that either $w$ or $v$ is the actual world, but cannot decide between the two. When he figures out which trail he is looking at, he narrows down his (propositional) knowledge from $\{w, v\}$ to $\{w\} .{ }^{10}$ Lewis' argument thus seems to amount to stipulate first that propositions cannot distinguish between the cases of this sort, and then go on to argue, granted this stipulation, that "propositions won't do." 11

\footnotetext{
${ }^{10}$ In other words, Brian and Bill may be omniscient over general propositions, but if they do not know what to do, they are not omniscient over singular propositions. (Note that if $w$ and $v$ are not isomorphic, then Brian and Bill will also lack knowledge of general propositions.)

${ }^{11}$ Lewis wrote for instance: "I claim that sometimes the agent has alternative possibilities in a single world. Consider Lingens [Perry's amnesiac lost in the Stanford Main Library] when he knows almost enough to get out. He has narrowed the possibilities down to two. Perhaps he is in aisle five, floor six, of Main Library, Stanford, in which case the way out is to go downstairs. Or perhaps he is on one of the lower floors in the stacks of Widener, in which case the thing to do is go up. The books tell him that there are amnesiacs lost in both places, and he has figured out that he is one of the two. (...) The good case 1 [in which Lingens is the Stanford amnesiac] and the bad case 3 [in which Lingens is the Widener amnesiac], for instance, do not belong to different worlds. They are separated by about 3000 miles within a single world." [1], p. 149. If one weakens the notion of possible world so as to conflate the state of affairs in which Lingens is in Stanford with the state of affairs in which he in Widener,
} 


\section{Conclusion}

When Perry and Lewis questioned it, the naive doctrine was seen as the received view. Since then, the idea that propositions are not powerful enough to model belief and account for behavior has become something of a received view itself. I have argued that the problem of the essential indexical does not refute the naive doctrine. Every time we came upon an agent who, under the same circumstances, assumed different behaviors, we were able to distinguish his beliefs by means of some proposition. ${ }^{12}$ Propositions about ordinary things, like you, me or the Mt. Tallac trail, most often do the trick. When they do not, others, whose truth depends on things such as mental events, do. Note that the naive doctrine does not need special constraints on the cognitive relation borne to the mental events involved in the propositions believed. The conditions for direct reference remain the same regardless of whether the things referred to happen to be mental events, other sorts of events, or other sorts of particulars. Now, it is not excluded that the mental events that allow for direct reference should be de facto the same events as the ones that are undergone at the time of reference - that is an empirical question.

Two lessons have emerged from the problem of the essential indexical. One has to do with ensuring that a given agent will act upon a certain thing rather than another. For this, we need tools analogous to those supplied by the notion of de re belief. The other has to do with the relationship between indexicals, which are linguistic devices for expressing beliefs, and the beliefs expressed. It has emerged that the role of an indexical often goes beyond the thing that the indexical stands for in a given context. Key roles may be conferred on the agent's relation to that thing, rather than to the thing itself.

The problem of the essential indexical is not an insuperable problem for the naive doctrine. It shows that heed should be paid to what is acted upon as a result of some belief. Singular propositions allow us to do that, as does any mechanism of direct reference. Nothing should go wrong, then, in taking propositions for objects of belief, as long as we keep an eye on the conditions under which one can come to believe a singular proposition. The problem also shows that care is to be taken not only of the relations that come with the predicate, but also of the relations that come with the indexicals with whose help some belief is expressed. And to take care of them, we need nothing more than propositions tout court. ${ }^{13}$

of course one will be likely to have difficulties in modeling beliefs with possible worlds. But there is no reason why these states of affairs should correspond to one possible world rather than two distinct ones. The reason Lewis finds is that it would commit him to haecceitism. But I doubt this is a valid reason. The issue of cross-world identification is a metaphysical issue, whereas the problem of the essential indexical is more of a technical issue, since the question it addresses is whether belief can be modeled within propositional frameworks.

${ }^{12}$ Have I shown that for every single possible case of the sort, there actually exists a suitable proposition? Well, I have indicated a method of generating a suitable proposition upon the parameters of the case. Since problematic cases appear to arise only when something has been identified under different guises, the clue is to turn those guises into relations proper, which may then be incorporated into the proposition sought.

${ }^{13}$ I am indebted to David Chalmers, John Perry, François Recanati and Philippe Schlenker for comments on an earlier draft. 


\section{References}

1. Lewis, D.: Attitudes De Dicto and De Se, in Collected Papers, Oxford UP (1993)

2. Perry, J.: The Problem of the Essential Indexical, Noûs 13 (1979), reprinted in [4]

3. Perry, J.: Thought without Representation, Supplementary Proceedings of the Aristotelian Society 60 (1986), reprinted in [4]

4. Perry, J.: The Problem of the Essential Indexical, Oxford UP (1993)

5. Russell, B.: Knowledge by Acquaintance and Knowledge by Description, Proceeding of the Aristotelian Society 11 (1910), reprinted in [6]

6. Salmon N., Soames S. (eds.), Propositions and Attitudes, Oxford UP (1988)

7. Stalnaker R.: Indexical Belief, Synthese 49 (1981) 